\title{
Testosterone, personality traits and aggressive driving among young male drivers
}

\author{
Sucha $\mathrm{M}^{1}$, Pillerova $\mathrm{M}^{2}$, Dominik $\mathrm{T}^{1}$, Vaculcikova Sedlackova $\mathrm{Z}^{1}$, Renczes $\mathrm{E}^{2}$, \\ Hodosy $\mathrm{J}^{2,3}$, Tothova $\mathrm{L}^{2}$ \\ Department of Psychology, Faculty of Arts, Palacky University in Olomouc, Olomouc, Czech Republic. \\ lubomira.tothova@imbm.sk
}

\begin{abstract}
INTRODUCTION: Psychological testing to examine potentially aggressive behaviour is a gold standard, but it is not sufficient. Testosterone might increase an aggressive behaviour.

AIM: The aim of this study was to evaluate whether testosterone along with psychological assessment of fitness to drive could help to identify aggressive drivers.

METHODS: Male participants $(n=150)$ aged from 20 to 25 , who possessed a driving license and drive at least $100 \mathrm{~km}$ per week, were evaluated in this study using an Inventory of traffic-relevant personality characteristics, the Sensation Seeking Scale and the Buss-Durkee Aggression Inventory. Saliva was collected for testosterone and cortisol measurements. The five binomial logistic models with dependent variables Caused an accident, Driving license taken away, Court trial, Intoxicated driving and Sporty self-report were tested in this study.

RESULTS: The 'Intoxicated driving' model, was found to be statistically highly significant, explaining $48.8 \%$ of the dependent variable's variance $\left(X^{2}(16)=36.145, p<0.01\right)$. In this model with sensation seeking, actual testosterone and their interaction was highly significant and explained $20.4 \%$ of intoxicated driving variability $\left(X^{2}(3)=14.283, p<0.01\right)$. This was higher than sensation seeking scores only.

CONCLUSION: To conclude, salivary testosterone might prove a biological marker that improves the identification of those with a high probability of aggressive driving or its subtypes (Tab. 3, Ref. 53). Text in PDF www.elis.sk

KEY WORDS: testosterone, traffic psychology, aggressive behaviour, traffic safety, young drivers.
\end{abstract}

\section{Introduction}

Aggressive driving is defined by the US National Highway Traffic Safety Administration (1) as the behaviour of an individual, who commits a combination of moving traffic offences to endanger other persons or property. A driving behaviour is aggressive if it is deliberate, likely to increase the risk of collision and is motivated by impatience, annoyance, hostility and/or an attempt to save time (2). The traffic safety and psychological literature specifically on aggressive driving suggests several other factors that increase the likelihood of aggressive driving behaviour. These include relatively young age, male gender and traffic

${ }^{1}$ Department of Psychology, Faculty of Arts, Palacky University in Olomouc, Olomouc, Czech Republic, ${ }^{2}$ Institute of Molecular Biomedicine, Faculty of Medicine, Comenius University, Bratislava, Slovakia, and ${ }^{3}$ Institute of Physiology, Faculty of Medicine, Comenius University, Bratislava, Slovakia

Address for correspondence: L. Tothova, Ass Prof, Dr, PhD, Institute of Molecular Biomedicine, Faculty of Medicine, Comenius University, Sasinkova 4, SK-813 72 Bratislava, Slovakia.

Phone: +421.2 .59357296$

Acknowledgements: The study was funded by Slovak Research and Development Agency, grant No. APVV-0539-12 and by Czech Ministry od Education, Yuth and Sports for specific research IGA_FF_2021_018. situations that confer anonymity and/or, where escape is highly likely (3). In addition, a personality that predisposes an individual to sensation seeking or aggressiveness in other social situations might play a role (4).

To be more specific, the profile of high risk driver established by the Traffic Injury Research Foundation (5) has revealed some prominent characteristics: young, male, employed, low to moderate income, other safety-compromising behaviours, thrill seeking, aggressive, and record of previous traffic violations and crashes. It appears there are three high-risk groups: young drivers (less than 25 years old), hard-core drinking drivers, and drivers with previous violations and crashes (6).

Besides psychological variables, biological approaches can aid in our understanding of interindividual differences in traffic violations. While individuals vary greatly in their tendency to take risks, men tend to engage in more risky behaviour than women do across a variety of contexts (7). Apart from the masculinisation effect, testosterone (TST) as the main male gonadal hormone is a steroid hormone that acts on the central nervous system (CNS). Its role is to organise and to activate neural circuits. Increased endogenous levels of TST seem to encourage dominant behaviour to such extent that it might result in an elevated aggressive behaviour $(8,9)$. While animal studies are consistent with a strong evidence 
that high levels of TST can be related to high aggressiveness (10), there are some inconsistencies in humans (11-14).

This inconsistency might be driven by the complex hormonal pathway of testosterone. Firstly, the effect of testosterone on the neurodevelopment is well documented. The brain structures that can be modified early due to foetal testosterone include hypothalamus, hippocampus or dentate gyrus (15). The organization change of brain due to testosterone might have influence on activational effects of testosterone later, in adulthood (16). Indeed, measuring foetal testosterone is extremely difficult if possible, at all. At least in humans. The prenatal testosterone can be predicted only indirectly by a ratio of a second to fourth digit (17). Although this tool is far from ideal, low 2D:4D ratio is linked to maternal high testosterone environment and may be responsible for several disorders such as: autism (18), impulsivity (19) or aggression (20).

Activational effects of TST are crucial during adolescence and adulthood when TST is being secreted. Apart from other organs, testosterone targets the central nervous system (21). In adulthood, these effects activate the relevant adult behavioural and physiological pathways obtained by organisational effects (22). Unlike organisational effects, these effects were identified as acute and reversible (21). According to many articles, adult males with higher levels of actual TST present with a more aggressive behaviour $(11,12,23)$. On the other hand, the links between an aggressive behaviour in humans and testosterone were found to be significant, but relatively weak (24). This finding might be due to the fact that majority of studies used only baseline determination of testosterone. However, as it is known, testosterone undergoes significant daily fluctuations that might be more important than baseline value itself (25).

Cortisol, as another steroid and stress hormone, can further modulate the relationship between TST and aggression, at least in male adolescents (26). A positive relationship was found between TST and overt aggression in subjects with low cortisol levels (27). Such an effect is referred to as the dual hormone hypothesis, and was first described in 2010 (28).

Although $95 \%$ road traffic accidents are co-caused by human factors, it is still impossible to determine the correlations and significance of individual human attributes (as personality traits), behavioural patterns and qualities that are responsible for accidents, due to the immense number of relevant and intervening effects (29). The relationship between the road traffic accidents rate and driver personality has not been sufficiently explained. Despite a large body of studies, findings have been either conflicting or of little importance (30). One of the most promising constructs is the Sensation Seeking Scale (SSS), a personality trait of thrill seeking behaviour (31). Drunk driving behaviour among young males has been related to sensation seeking as well as egocentrism (32). This measure has been found to correlate with many types of risk taking behaviour, like driving speed and self-reported traffic violations (33).

In this context, we hypothesised that the actual concentration of testosterone along with cortisol and/or testosterone daily change might correlate with a potential aggressive driving among young individuals. Thus, the aim of this study was to evaluate current psychological predictive tests of aggressive behaviour together with actual and prenatal concentrations of testosterone and corti- sol. The improvement of such a prediction could have a significant effect on the current processes of driver evaluation.

\section{Subjects and methods}

\section{Subjects}

Data about participants from psychological tests and nonbiochemical measurements were acquired from the Department of Psychology, Faculty of Arts, Faculty of Philosophy of Palacky University Olomouc, Czech Republic. The Ethical committee of Palacky University approved the study, and all the participating subjects signed an informed consent. The participants were recruited for the study by advertisements on relevant social networks groups and by leaflets handed out at the university or public premises (libraries, refectory, etc.). Overall, 150 consecutively enrolled drivers were included in the study. Inclusion criteria were as follows: 1. possession of a driving license, 2. male gender, 3 . age 20 to 25,4 . drives at least $100 \mathrm{~km}$ per week. The evaluation of participants took about two hours, from 8:00 AM until 10:00 AM. All the participants underwent all the following measurements and questionnaires.

\section{D:4D ratio}

Both palmar surfaces of the participants hands were scanned using a desktop scanner. Later, the images were evaluated by two blinded examiners. The ratio was calculated as the distance from the base of proximal phalanx to the corresponding tip of the 2nd and 4 th fingers. The data from two examiners were averaged, with the interobserver variability of less than $5 \%$.

\section{Saliva sample collection}

Whole unstimulated saliva was collected for ten minutes using $15 \mathrm{ml}$ tubes. The participants were instructed to abstain from eating, drinking (not counting water), chewing gum or brushing their teeth for at least $30 \mathrm{~min}$ (34). Due to circadian rhythms in steroid hormones, saliva collection took place at 8:00 AM for all the participants. The second collection of saliva for testosterone measurement was conducted by the same manner as the first collection after the psychological testing ended, i.e. between 9:30 AM to 10:00 AM. Collected saliva samples were stored at $-20^{\circ} \mathrm{C}$ until analyses were performed. The exclusion criteria for saliva collection were reported oral disease, inflammation or lesion and visible blood contamination. All are the factors that could interfere with the hormonal measurement (35).

\section{Sociodemographic questionnaire}

The participants were asked about following specifics: year of birth, height, weight, education, monthly income, having a partner/ husband/wife, living with a partner/husband/wife, having a serious disease, medication use, food supplements, daily physical activity, self-evaluation of own driving (driving fast/sporty, carefully/considerate), dominant arm, committing a traffic offense/crime in the last five years and what kind of offense/crime, number of traffic accidents and number of traffic accidents caused in the last five years, previous driving license withdrawal, being judged for an offense/crime, and driving under the influence of drugs/alcohol (36). 
Inventory of traffic-relevant personality characteristics (shortened version - TVP)

The TVP is an inventory used for measuring personality dimensions that are relevant for mental eligibility to drive a car. It is based on the NEO personality model, which includes the dimensions neuroticism, extraversion, openness to experience, agreeableness, and consciousness. The TVP contains general dimensions based on NEO BIG-5, as well as dimensions specific to certain traffic situations. There are also bagatellisation and reactance scales. It contains 129 items. Respondent rates each item on a four-point scale, from 'fit not at all', to 'fit entirely' (37).

\section{Sensation Seeking Scale form V (SSS-V)}

The SSS-V is a method for detecting the tendency to seek new experiences and to adapt to new things/situations/changes in lifestyle. It includes four subscales: seeking for tension and adventure, seeking for experience, disinhibition, and perception of boredom. It contains 40 items. Each item includes two choices, from which the respondent must choose one possibility. The respondent chooses the possibility that corresponds more with his/ her hobbies or feelings (38).

\section{Buss-Durkee aggression inventory (BDI)}

The BDI inventory is used for the diagnostics of aggression and hostility. It consists of 75 items. The respondent agrees or a complex phenomenon, so the inventory contains a number of disagrees with each item. The authors understand aggression as

subscales: physical aggression, indirect aggression, irritability, negativism, resentment, suspiciousness, verbal aggression and feelings of guilt (39).

\section{Biochemical analysis}

Collected saliva samples were centrifuged at 2,000 x $\mathrm{g}$ for $10 \mathrm{~min}$ at $4{ }^{\circ} \mathrm{C}$ and the supernatant was used for further analysis. Hormonal measurements were performed using commercially available ELISA kits (DRG Diagnostic, SLV-3013 for testosterone and SLV-4635 for cortisol, Marburg, Germany) according to manufacturer's protocol. The intra-assay variability of testosterone was $8.16 \%$ and the inter-assay variability was $7.62 \%$. The intra-assay variability for cortisol was $2.62 \%$ and the inter-assay variability was $6.65 \%$.

\section{Statistical analysis}

The data were transformed into a data matrix, where only relevant data were kept. One participant was excluded from the study, due to corticosteroid medication. Overall, the analysis was performed on 149 participants.

We selected five dependent variables, which we assumed to reflect a driver's tendency toward aggressive behaviour:

1. Caused an accident - scored as 1 if the driver reported having caused an accident during in the last five years and 0 if not.

2. Driving license taken away - scored as 1 if the driver reported having his driving license taken away at any time in the past and 0 if not.

Tab. 1. Results of binomial logistic regression model for the dependent variable 'Caused an accident'. None of the factors or factor interactions was found to have a significant effect on whether or not the participant reported having caused an accident.

\begin{tabular}{lcccc}
\hline & $\mathrm{b} \pm 95 \% \mathrm{CI}$ & $\mathrm{SE}$ of b & Wald test & $\mathrm{p}$ \\
\hline intercept & $-0.335 \pm 3.273$ & 1.670 & 0.040 & 0.841 \\
physical aggression & $0.120 \pm 0.226$ & 0.115 & 1.084 & 0.298 \\
irritability & $-0.023 \pm 0.337$ & 0.172 & 0.018 & 0.893 \\
sensation seeking & $-0.005 \pm 0.061$ & 0.031 & 0.030 & 0.863 \\
general emotional lability & $0.222 \pm 0.359$ & 0.183 & 1.462 & 0.227 \\
traffic-specific emotional lability & $-0.315 \pm 0.454$ & 0.232 & 1.849 & 0.174 \\
reactance & $-0.158 \pm 0.258$ & 0.132 & 1.440 & 0.230 \\
cortisol & $-0.790 \pm 1.580$ & 0.806 & 0.961 & 0.327 \\
TST-actual & $-1.803 \pm 7.699$ & 3.928 & 0.211 & 0.646 \\
TST-change & $-0.003 \pm 0.008$ & 0.004 & 0.508 & 0.476 \\
TST-actual*cortisol & $0.414 \pm 3.211$ & 1.638 & 0.064 & 0.800 \\
TST-actual*general emotional lability & $-0.216 \pm 0.781$ & 0.399 & 0.295 & 0.587 \\
TST-actual*traffic-specific emotional lability & $0.472 \pm 1.078$ & 0.550 & 0.737 & 0.391 \\
TST-actual*reactance & $-0.172 \pm 0.551$ & 0.281 & 0.375 & 0.540 \\
TST-actual*irritability & $-0.575 \pm 0.854$ & 0.436 & 1.741 & 0.187 \\
TST-actual*sensation seeking & $0.096 \pm 0.157$ & 0.080 & 1.425 & 0.233 \\
TST-actual*physical aggression & $-0.092 \pm 0.451$ & 0.230 & 0.158 & 0.691 \\
\hline
\end{tabular}

3. Court trial - scored as 1 if the driver reported having been subjected to a court trial because of a legal offense of any kind and 0 if not.

4. Intoxicated driving - scored as 1 if the driver reported having driven intoxicated by any drug at any time in the past and 0 if not. 5. Sporty self-report-scored as 1 if the driver self-reported to be a 'dynamic/sporty' driver and 0 if reported as a 'cautious/considerate' driver.

We explored, which of the following biological and psychological factors could predict the dependent variables with a statistically significant accuracy. The biological factors were TST-actual (actual testosterone level measured before testing), and cortisol (actual cortisol level measured before testing). The psychological factors were gen-

Tab. 1S. Descriptive data for measured variables.

\begin{tabular}{|c|c|c|c|c|c|c|c|c|}
\hline & $\begin{array}{c}\text { BDI1 physical } \\
\text { aggression }\end{array}$ & $\begin{array}{c}\text { BDI3 } \\
\text { iritability }\end{array}$ & SSS Overall & $\begin{array}{l}\text { TVP Emotional } \\
\text { lability general }\end{array}$ & $\begin{array}{c}\text { TVP Emotional } \\
\text { lability traffic specific }\end{array}$ & $\begin{array}{c}\text { TVP } \\
\text { reactance }\end{array}$ & $\begin{array}{c}\mathrm{TST} \\
\ln \end{array}$ & $\begin{array}{c}\text { Cortisol } \\
\ln \end{array}$ \\
\hline mean (data centered) & 0.0 & 0.0 & 0.0 & 0.0 & 0.0 & 0.0 & 0.0 & 0.0 \\
\hline $\mathrm{SD}$ & 2.6829 & 2.1083 & 10.3698 & 2.6415 & 2.1292 & 2.3375 & 0.505 & 0.354 \\
\hline $\min$ & -3.8658 & -4.2463 & -23.5503 & -3.5638 & -3.3758 & -4.4362 & -1.383 & -0.901 \\
\hline $\max$ & 6.1342 & 5.6537 & 30.4497 & 4.4362 & 4.6242 & 3.5638 & 1.231 & 0.794 \\
\hline
\end{tabular}

Data are centered. BDI - Buss-Durkee aggression inventory, TVP - Inventory of traffic-relevant personality characteristics, SSS - Sensation seeking scaled, TST - testosterone, $\mathrm{SD}$ - standard devation, min - minimal value, max - maximal value 
eral emotional lability (subscale from the TVP questionnaire), traffic-specific emotional lability (subscale from the TVP questionnaire), reactance (subscale from the TVP questionnaire), tendency to physical aggression (subscale from the B-D-I questionnaire), irritability (subscale from the B-D-I questionnaire), and tendency to sensation seeking (overall score in the SSS questionnaire).

Due to the extreme skewness of the biological data, the variables TST-actual and cortisol were transformed using a natural logarithm (Supplementary Table 1S). Ten values from the logtransformed TST-actual and two values from the log-transformed cortisol variables were removed as outliers based on the Tukey $1.5 x I Q R$ rule. Dependent variables contained missing data: 5 values in caused an accident, 18 values in driving license taken away, 18 values in court trial and 18 values in intoxicated driving.

Five binomial logistic models were planned to be employed, one for each dependent variable. In the models, which were successfully constructed, the alpha level was always set to be 0.05 and no p-value corrections were applied. Besides including the main effects of the stated factors, we also expected interactions of several factors, so we also included the following interactions: TST-actual*cortisol, TST-actual *general emotional lability, TSTactual*traffic-specific emotional lability, TST-actual*reactance, TST-actual*physical aggression, TST-actual*irritability and TSTactual* ${ }^{*}$ sensation seeking. Factors were introduced to the model by the entry method. All the factors, both biological and psychological, were centred by subtracting their mean before being included into the model so that the intercept reflects, hyperbolically speaking, a young adult male with an average testosterone level, average cortisol level, average self-control and average dominance. If a meaningful relationship was discovered, a series of customised exploratory analyses were employed, such as model contraction with the aim of assessing how much additional variability is explained if a biological measure is added to a psychological one.

\section{Results}

\section{Prediction of 'Caused an accident'}

The binomial logistic model using stated factors and factor interactions to predict whether the participant reported having caused an accident was found to be statistically insignificant, $\chi^{2}(16)$ $=10.901, \mathrm{p}=0.816$, explaining only $17.1 \%\left(\right.$ Nagelkerke $\left.\mathrm{R}^{2}\right)$ of the dependent variable's variance while correctly classifying $15.0 \%$ of respondents, who reported having caused an accident and $97.3 \%$ of respondents, who did not. For detailed results (Tab. 1).

\section{Prediction of 'Driving license taken away' and 'Court trial'}

The analyses could not be carried out because, out of 131 participants, who answered the questions, only two reported having had their driving license taken away in the past and only six reported having been subject to a court trial due to a legal offense. Therefore, these analyses were omitted (Supplementary Table 2S).

\section{Prediction of 'Intoxicated driving'}

The binomial logistic model was found to be statistically highly significant, $\chi^{2}(16)=36.145, p=0.003$, explaining $48.8 \%$ (Nagelkerke $\mathrm{R}^{2}$ ) of the dependent variable's variance and correctly classifying $60.0 \%$ of participants, who reported driving while intoxicated and $88.5 \%$ of those, who did not report this. The results showed several significant relationships. The higher tendency to sensation seeking was positively associated with the reported experience with driving as intoxicated. The opposite connection was found for TST-actual, i.e. lower testosterone concentrations were connected to a higher likelihood of reporting driving as intoxicated. Interestingly, a positive interaction effect of sensation seeking*TST-actual was also found, suggesting that the positive effect of sensation seeking is stronger if the testosterone concentration is higher. Additionally, a significant negative main effect of TST-change was found, suggesting that a greater decrease in the testosterone level during testing is connected with a higher likelihood of reporting intoxicated driving. Finally, our results also suggest a significant positive interaction of TST-actual ${ }^{*}$ cortisol. For detailed results (Tab. 2).

The model containing sensation seeking only was significant, $\chi^{2}(1)=6.092, \mathrm{p}=$ 0.014 , and explained $9.1 \%$ (Nagelkerke $\mathrm{R}^{2}$ )

Tab. 2S. The frequency of self-reported events.

\begin{tabular}{|c|c|c|c|c|c|c|}
\hline & Type of driver (self-report) & & Caused an accident & Driving license taken away & Court trial & Driving intoxicated \\
\hline agile, sporty & 81 & Yes & 31 & 2 & 6 & 43 \\
\hline careful, respectful & 68 & No & 113 & 129 & 125 & 88 \\
\hline
\end{tabular}


Tab. 3. Results of binomial logistic regression model for the dependent variable 'Sporty selfreport'. Significance is denoted as follows: * denotes $p<0.05$, ** denotes $p<0.01$.

\begin{tabular}{lcccc}
\hline & $\mathrm{b} \pm 95 \% \mathrm{CI}$ & $\mathrm{SE}$ of b & Wald test & $\mathrm{p}$ \\
\hline intercept & $-2.530 \pm 3.086$ & 1.575 & 2.580 & 0.108 \\
physical aggression & $-0.196 \pm 0.219$ & 0.112 & 3.090 & 0.079 \\
irritability & $0.312 \pm 0.327$ & 0.167 & 3.503 & 0.061 \\
sensation seeking & $0.023 \pm 0.053$ & 0.027 & 0.685 & 0.408 \\
general emotional lability & $0.024 \pm 0.333$ & 0.170 & 0.020 & 0.888 \\
traffic-specific emotional lability & $-0.184 \pm 0.430$ & 0.220 & 0.702 & 0.402 \\
reactance & $0.351 \pm 0.255$ & 0.130 & 7.275 & $0.007 * *$ \\
cortisol & $0.895 \pm 1.371$ & 0.700 & 1.636 & 0.201 \\
TST-actual & $-4.358 \pm 7.163$ & 3.655 & 1.422 & 0.233 \\
TST-change & $0.003 \pm 0.008$ & 0.004 & 0.419 & 0.517 \\
TST-actual*cortisol & $0.985 \pm 2.959$ & 1.510 & 0.426 & 0.514 \\
TST-actual*general emotional lability & $-0.780 \pm 0.843$ & 0.430 & 3.290 & 0.070 \\
TST-actual*traffic-specific emotional lability & $1.050 \pm 1.076$ & 0.549 & 3.660 & 0.056 \\
TST-actual*reactance & $-0.303 \pm 0.484$ & 0.247 & 1.507 & 0.220 \\
TST-actual*irritability & $0.080 \pm 0.716$ & 0.365 & 0.048 & 0.827 \\
TST-actual*sensation seeking & $0.062 \pm 0.128$ & 0.065 & 0.904 & 0.342 \\
TST-actual*physical aggression & $0.389 \pm 0.460$ & 0.235 & 2.756 & 0.097 \\
\hline
\end{tabular}

quences on public health and safety. Although the number of traffic crashes with fatalities has been decreasing or stagnating in most European countries in last 10 years, road crashes still account for one of the most important preventable causes of death. When ranked by specific ages, in 2015, motor vehicle traffic crashes were the leading cause of unintentional injury and death among males for every age from 5 to 23 years (40). Crash death rates for drivers under 25 are roughly double than those of older drivers. Young men are particularly at risk, with death rates of up to three times those of young women. Many crashes are the result of speeding, and while driving under the influence of alcohol or drugs. Young people are over-represented in single-car and loss-of-control crashes, and

of the variability in reported intoxicated driving. The model containing both sensation seeking and actual testosterone, as well as their interaction, was highly significant, $\chi^{2}(3)=14.283, p=0.003$, and explained $20.4 \%$ (Nagelkerke $\mathrm{R}^{2}$ ) of intoxicated driving variability (directions of the effects remain the same as in the full model reported above).

\section{Prediction of 'Sporty self-report'}

The binomial logistic model predicting whether the participant self-reported as a sporty/dynamic driver was found to be statistically significant, $\chi^{2}(16)=28.805, p=0.026^{*}$, explaining $34.3 \%$ (Nagelkerke $\mathrm{R}^{2}$ ) of the self-report variance and correctly classifying $82.4 \%$ of those participants, who self-reported as sporty/ dynamic and $65.9 \%$ of those who self-reported as cautious/considerate. We found a highly significant positive effect of reactance, suggesting that higher levels of this personality trait are related to a higher likelihood of self-reporting as a sporty/dynamic driver. For detailed results see Table 3 .

\section{Prenatal testosterone, testosterone change and cortisol con- centrations}

Apart from the results mentioned above, other analysis showed non-significant differences or change. More specifically, the ratio of 2 nd digit to 4 th digit as a marker of prenatal testosterone seemed to be nonsignificant in all the performed analysis. Also, a change in testosterone between the baseline values and after the testing at 10:00 AM did not reveal any significant interactions with the performed analysis. Additionally, apart from an intoxicated driving, the testosterone cortisol interaction was not significant in any other analysis.

\section{Discussion}

Driving a motor vehicle is one of the most common activities of adults. However, human driving behaviour has direct conse- crashes where the driver is turning across oncoming traffic (41). All these causes relate to (and are defined as) aggressive driving.

TST should have a significant impact on aggressive behaviour in adulthood $(11,12)$. Human studies are suggesting that TST itself does not directly cause aggressive or anti-social behaviour, but induces chemical changes in specific neurons, influencing the likelihood of specific behavioural outcomes as the result of the modulation of neural pathways in the amygdala and hypothalamus (42). Also, several studies point towards a weak link between testosterone and aggressive behaviour, while suggesting testosterone fluctuations to be more important than its actual concentrations (43). The experimental findings of Carré and colleagues demonstrated that TST can rapidly increase an aggressive behaviour, but only among dominant and impulsive males (23). One of the factors that makes people behave regularly and persistently in a variety of situations is personality. Besides other factors, such as beliefs, norms or motivations, personality traits are said to constitute human personality. Efforts have been made to explain what 'lies behind the behaviour', or 'what steers behaviour' and how can this be measured with behaviour personality inventories. Arnett et al found that both dominance and impulsivity are significantly related to aggressive driving behaviours such as driving $20 \mathrm{mph}$ or more over the speed limit, racing with another car, passing in a no passing zone or driving under the influence (32). Also, sensation seeking and aggressiveness are significantly correlated with adolescents scoring higher than adults and male adolescents scoring higher than female adolescents (Arnett, 1996), suggesting that testosterone might play a role (44).

In our study, we aimed to improve the identification of individuals, who can be considered as risky drivers. Using binomial models with dependent variables, i.e. potential outcomes or associations of risky driving, such as Caused an accident, Driving license taken away, Court trial, Intoxicated driving and Sporty self-report, we constructed a model that might help to predict one subtype of the risky driving, i.e. driving under the influence of alcohol and other drugs (45). Sensation seeking as a valid personality trait was positively correlated with intoxicated driving. However, it is interest- 
ing that testosterone was negatively associated with the reported intoxicated driving, since it is believed that testosterone is linked with aggressive behaviour. For example, Welker et al found the opposite, i.e. a positive correlation with testosterone and aggressive behaviour, similar to several other studies (46). It is important to note that growing evidence suggests that testosterone plays a modulating role in an 'optimal' environment. That is, high testosterone levels can indeed induce aggression, but simultaneously a personality condition must be met. In our study, volunteers who scored highly in sensation seeking, higher testosterone also predisposed them to reporting the intoxicated driving more. This would explain rather a negative correlation of testosterone and self-reports of driving as intoxicated. However, without any link to sensation seeking. This would suggest that without a social predisposition to act aggressively, the testosterone itself cannot fully explain an aggressive behaviour (47). In this context, we found also a significant interaction of actual testosterone and cortisol that were also positively correlated with self-reporting of intoxicated driving. This interaction is better known as a dual-hormone hypothesis. Although some of the studies point that a high testosterone increase aggression, but only when cortisol levels are low (48), the high testosterone - high cortisol interaction has been found as well (49). The latter study suggests that cortisol affects sensitivity in socially threatening situations. This means that when under long-term social stress and high cortisol environment, the higher testosterone might induce an aggressive response at higher rate (50). Nevertheless, this interaction was significant, but quite weak. Similarly, increasing number of reports emphasize testosterone fluctuations and not actual testosterone to be responsible for aggressive behaviour (47). We tried to implement the design of the study to reflect this. The second saliva collection was performed just when the testing finished during a narrow time window to reflect diurnal testosterone fluctuations. Nevertheless, such testosterone change in our study was significant in one of the self-reported aggressive driving, but the association was weaker, when compared to actual testosterone. Therefore, according to the results, and based on the suggestive discovery of an interaction between the actual testosterone level and sensation seeking, we asked the question to what extent can intoxicated driving be attributed to sensation seeking itself and how much more information we can obtain if the testosterone level is considered as well. To answer this question, we constructed two contracted binomial logistic models, one containing sensation seeking only, and the other containing sensation seeking, the actual testosterone level and their interaction. The latter proved to be highly significant and explained more of the variability, when compared to the sensation seeking alone (20.4\% vs $9.1 \%$, respectively).

This study had some limitations, such as the salivary measurement of testosterone instead of plasma testosterone. Nevertheless, several authors showed a good correlation between testosterone levels in saliva and plasma $(51,52)$. We tried to avoid all common mistakes such as food or drinks before testing, thus eliminating variability in saliva by giving clear instructions for saliva collection $(34,35)$. Additionally, the aim of this study was to help with identification of aggressive drivers. Blood collection could represent a stress, while saliva collection is easy and non-invasive (53).
Also, the population included males within 20-25 years old, i.e. one age group with the highest testosterone, so these results cannot be automatically generalized to other age groups. On the other hand, the 20-25 year old age group was considered the riskiest in terms of aggressive driving, and this is the first study according to our best knowledge that evaluated biological factors in relation to psychological testing. Indeed, we are aware that some of the analyses ( 2 and 3 ) could not be run because of the small number of participants with a positive self-reported aggressive/reluctant behaviour.

In conclusion, in this study, we showed that adding testosterone to the psychological assessment of fitness to drive might improve the diagnostic accuracy, when added to the psychological testing alone. At least in some of the predictive models. Indeed, the testosterone level was useful in explaining aggressive behaviour only in individuals that were predisposed to act aggressively according to the Sensation Seeking Scale. Since the reports dealing with the drivers' history (e.g. crashes, violations, driving license withdrawn) were based on self-reporting, validating studies including more drivers from all age groups should be performed.

\section{References}

1. Stustert J. Aggressive Driving Enforcement: Evaluation of Two Demonstration Programs. National Higway Traffic Safety Administration 2004; DOT HS 809707.

2. Dula CS, Geller ES. Risky, aggressive, or emotional driving: addressing the need for consistent communication in research. J Safety Res 2003; 34 (5): 559-566.

3. Massie DL, Campbell KL, Williams AF. Traffic accident involvement rates by driver age and gender. Accident Analysis Prevention 1995; 27 (1): 73-87.

4. Wilson LC, Scarpa A. The link between sensation seeking and aggression: a meta-analytic review. Aggres Behav 2011; 37 (1): 81-90.

5. Robertson L. Road death trend in the United States: implied effects of prevention. J Publ Health Policy 2018; 39 (2): 193-202.

6. Simpson HM, Beirness DJ, Robertson RD, Mayhew DR, Hedlund JH. Hard core drinking drivers. Traffic Injury Prev 2004; 5 (3): 261-269.

7. Byrnes JP, Miller DC, Schafer WD. Gender Differences in Risk Taking: A Meta-Analysis. Psycholl Bull 1999; 125 (3): 367-383.

8. Chen FR, Raine A, Granger DA. Testosterone and Proactive-Reactive Aggression in Youth: the Moderating Role of Harsh Discipline. J Abnorm Child Psychol 2018; 46 (8): 1599-1612.

9. Eisenegger C, Naef M, Snozzi R, Heinrichs M, Fehr E. Prejudice and truth about the effect of testosterone on human bargaining behaviour. Nature 2010; 463 (7279): 356-359.

10. Rubinow DR, Schmidt PJ. Androgens, brain, and behavior. Amer J Psychiat 1996; 153 (8): 974-984.

11. Archer $\mathbf{J}$. The influence of testosterone on human aggression. Brit $\mathbf{J}$ Psychol 1991; 82 (Pt 1): 1-28.

12. Simpson K. The Role of Testosterone in Aggression. McGill J Med 2001; 6: 32-40.

13. Book AS, Starzyk KB, Quinsey VL. The Relationship between Testosterone and Aggression: A Meta-analysis. Aggres Violent Behav 2001; 6 (6): 579-599.

14. Book AS, Quinsey VL. Re-examining the Issues: A Response to Archer et al. Aggres Violent Behav 2005; 10 (6): 637-646. 
15. Filova B, Ostatnikova D, Celec P, Hodosy J. The effect of testosterone on the formation of brain structures. Cells Tissues Organs 2013; 197 (3): 169-177.

16. Falter CM, Arroyo M, Davis GJ. Testosterone: activation or organization of spatial cognition? Biol Psychol 2006; 73 (2): 132-140.

17. de Sanctis V, Soliman AT, Elsedfy H, Soliman N, Elalaily R, Di Maio S. Is the Second to Fourth Digit Ratio (2D:4D) a Biomarker of Sex-Steroids Activity? Pediatr Endocrinol Rev 2017; 14 (4): 378-386.

18. Krajmer P, Spajdel M, Kubranska A, Ostatnikova D. 2D:4D finger ratio in Slovak autism spectrum population. Bratisl Med J 2011; 112 (7): 377-379.

19. Pearce E, Wlodarski R, Machin A, Dunbar RIM. Associations between neurochemical receptor genes, 2D:4D, impulsivity and relationship quality. Biol Lett 2018; 14 (12).

20. Kilduff LP, Hopp RN, Cook CJ, Crewther BT, Manning JT. Digit ratio (2D:4D), aggression, and testosterone in men exposed to an aggressive video stimulus. Evol Psychol 2013; 11 (5): 953-964.

21. Arnold AP. The organizational-activational hypothesis as the foundation for a unified theory of sexual differentiation of all mammalian tissues. Hormon Behav 2009; 55 (5): 570-578.

22. Romeo RD. Puberty: a period of both organizational and activational effects of steroid hormones on neurobehavioural development. J Neuroendocrinol 2003; 15 (12): 1185-1192.

23. Carre JM, Geniole SN, Ortiz TL, Bird BM, Videto A, Bonin PL. Exogenous Testosterone Rapidly Increases Aggressive Behavior in Dominant and Impulsive Men. Biol Psychiatry 2017; 82 (4): 249-256.

24. Archer J. Testosterone and human aggression: an evaluation of the challenge hypothesis. Neurosci Biobehav Rev 2006; 30 (3): 319-345.

25. McGlothlin JW, Jawor JM, Ketterson ED. Natural variation in a testosterone-mediated trade-off between mating effort and parental effort. Am Nat 2007; 170 (6): 864-875.

26. Fragkaki I, Cima M, Granic I. The role of trauma in the hormonal interplay of cortisol, testosterone, and oxytocin in adolescent aggression. Psychoneuroendocrinology 2018; 88: 24-37.

27. Popma A, Vermeiren R, Geluk CA et al. Cortisol moderates the relationship between testosterone and aggression in delinquent male adolescents. Biol Psychiatry 2007; 61 (3): 405-411.

28. Mehta PH, Josephs RA. Testosterone and cortisol jointly regulate dominance: evidence for a dual-hormone hypothesis. Hormon Behav 2010; 58 (5): 898-906.

29. Sommer M, Herle M, Häusler J, Risser R, Schützhofer B, Chaloupka C. Cognitive and personality determinants of fitness to drive. Transportation research part F: Traffic Psychol Behav 2008; 11 (5): 362-375.

30. Ranney TA. Models of driving behavior: a review of their evolution. Accident Analysis Prevention 1994; 26 (6): 733-750.

31. Zuckerman M, Neeb M. Sensation seeking and psychopathology. Psychiatry Res 1979; 1 (3): 255-264.

32. Arnett J. Drunk driving, sensation seeking, and egocentrism among adolescents. Personality Individual Differences 1990; 11 (6): 541-546.

33. Clément R, Jonah BA. Field dependence, sensation seeking and driving behaviour. Personality Individual Diff 1984; 5 (1): 87-93.

34. Durdiakova J, Fabryova H, Koborova I, Ostatnikova D, Celec P. The effects of saliva collection, handling and storage on salivary testosterone measurement. Steroids 2013; 78 (14): 1325-1331.
35. Kamodyova N, Banasova L, Jansakova K et al. Blood Contamination in Saliva: Impact on the Measurement of Salivary Oxidative Stress Markers. Dis Markers 2015; 2015: 479251.

36. Sucha M, Sramkova L, Risser R. The Manchester driver behaviour questionnaire: self-reports of aberrant behaviour among Czech drivers. Eur Transport Res Rev 2014; 6 (4): 493-502.

37. Caprara GV, Barbaranelli C, Hahn R, Comrey AL. Factor analyses of the NEO-PI-R Inventory and the Comrey Personality Scales in Italy and the United States. Personality Individual Differences 2001; 30 (2): 217-228.

38. Jonah BA. Sensation seeking and risky driving: a review and synthesis of the literature. Accident; Analysis Prevention 1997; 29 (5): 651-665.

39. Buss AH, Durkee A. An inventory for assessing different kinds of hostility. J Consulting Psychol 1957; 21 (4): 343-349.

40. Webb CN. Motor vehicle traffic crashes as a leading cause of death in the United States, 2015. Traffic Safety Facts Crash•Stats Report No DOT HS 812 499 2018: Washington, DC: National Highway Traffic Safety Administration.

41. Brief P. Young Drivers: The Road to Safety. OECD 2006; Retrieved on October 10, 2019 http://www.oecd.org/itf/37556934.pdf.

42. Sze Y, Gill AC, Brunton PJ. Sex-dependent changes in neuroactive steroid concentrations in the rat brain following acute swim stress. J Neuroendocrinol 2018; 30 (11): e12644.

43. Geniole SN, Bird BM, McVittie JS, Purcell RB, Archer J, Carre JM. Is testosterone linked to human aggression? A meta-analytic examination of the relationship between baseline, dynamic, and manipulated testosterone on human aggression. Hormon Behav 2020; 123: 104644.

44. Arnett JJ. Sensation seeking, aggressiveness, and adolescent reckless behavior. Personality Individual Differences 1996; 20 (6): 693-702.

45. Ulleberg P. Personality subtypes of young drivers. Relationship to risktaking preferences, accident involvement, and response to a traffic safety campaign. Transportation research part F: Traffic Psychol Behav 2001; 4 (4): 279-297.

46. Welker KM, Norman RE, Goetz S, Moreau BJP, Kitayama S, Carre JM. Preliminary evidence that testosterone's association with aggression depends on self-construal. Hormon Behav 2017; 92: 117-127.

47. Geniole SN, Carre JM. Human social neuroendocrinology: Review of the rapid effects of testosterone. Hormon Behav 2018; 104: 192-205.

48. Glenn AL, Raine A, Schug RA, Gao Y, Granger DA. Increased testosterone-to-cortisol ratio in psychopathy. J Abnorm Psychol 2011; 120 (2): 389-399.

49. Denson TF, Mehta PH, Ho Tan D. Endogenous testosterone and cortisol jointly influence reactive aggression in women. Psychoneuroendocrinology 2013; 38 (3): 416-424.

50. Denson TF, Ronay R, von Hippel W, Schira MM. Endogenous testosterone and cortisol modulate neural responses during induced anger control. Soc Neurosci 2013; 8 (2): 165-177.

51. Baxendale PM, Jacobs HS, James VH. Salivary testosterone: relationship to unbound plasma testosterone in normal and hyperandrogenic women. Clin Endocrinol (Oxf) 1982; 16 (6): 595-603.

52. Tanner AV, Nielsen BV, Allgrove J. Salivary and plasma cortisol and testosterone responses to interval and tempo runs and a bodyweight-only circuit session in endurance-trained men. J Sports Sci 2014; 32 (7): 680-689.

53. Kaczor-Urbanowicz KE, Martin Carreras-Presas C, Aro K, Tu M, Garcia-Godoy F, Wong DT. Saliva diagnostics - Current views and directions. Exp Biol Med (Maywood) 2017; 242 (5): 459-472.

Received February 27, 2021. Accepted March 3, 2021. 